\title{
Design and Analysis of a RFID Reader Microstrip Array Antenna for IoT Applications in Smart Cities
}

\begin{abstract}
Omaima Benkhadda, Laboratory of Automatic, Energy Conversion, and Microelectronics (LACEM), Faculty of Science and Technics, Universite Sultan Moulay Slimane, Morocco

Mohamed Saih, Laboratory of Automatic, Energy Conversion, and Microelectronics (LACEM), Faculty of Science and Technics, Universite Sultan Moulay Slimane, Morocco

kebir Chaji, Laboratory of Automatic, Energy Conversion, and Microelectronics (LACEM), Faculty of Science and Technics, Universite Sultan Moulay Slimane, Morocco

Abdelati Reha, Laboratory of Innovation in Management and Engineering for the Enterprise (LIMIE), ISGA, Marrakech, Morocco
\end{abstract}

\begin{abstract}
This paper presents the design of $2 * 1$ and $4 * 1$ RFID reader microstrip array antenna at $2.4 \mathrm{GHz}$ for the internet of things (IoT) networks which are Zigbee, Bluetooth, and WIFI. The proposed antenna is composed of identical circular shapes radiating patches printed in FR4 substrate. The dielectric constant $\varepsilon r$ and substrate thickness $h$ are 4.4 and $1.6 \mathrm{~mm}$, respectively. The $2 * 1$ and $4 * 1$ array antennas present a gain improvement of $27.3 \%$ and $61.9 \%$, respectively. The single, $2 * 1$, and $4 * 1$ array antennas were performed with CADFEKO.
\end{abstract}

\section{KEYWORDS}

Gain, IoT, Microstrip Array Antenna, Radiation Pattern, RFID

\section{INTRODUCTION}

Over the past few years, the IoT is a paradigm that uses information and communication technologies to make the interconnection of all objects in various domains such as healthcare, urban infrastructure, transportation, and energy. The IoT makes a large contribution in developing smart cities, most smart city applications use IoT devices equipped with sensors, actuators, and a limited computing capability (Fahmy et al., 2019; Khardioui et al., 2020; Varum et al., 2018).

To monitor physical objects while they are steady or on the move in smart city application, the Internet of Things employs various technologies to create a communication network between all this object such as radio-frequency identification (RFID) and near-field communication (NFC) (Khardioui et al., 2020).

The RFID is a smart technology that uses radio waves to monitor, identify, and follow objects. The RFID system contains a reader and a tag, which communicate between them by the air. The antenna is an important component of RFID systems. The RFID system depends on its performances such as gain and bandwidth(A.El Alami et al., 2019; Ali El Alami et al., 2005; Chen \& Qing, 2010; Ikram et al., 2017; Ouazzani et al., 2017). 
Recently various Research Projects microstrip antenna for IoT applications have been published, in (K. A. Nate et al., 2015)aperture coupling-fed antenna designed to be used in wireless sensors for IoT. A stretchable, flexible loop antenna operating at $2.4 \mathrm{GHz}$ ISM band, as a wearable solution for health and IoT applications is presented in (K. Nate \& Tentzeris, 2015). A dual-band microstrip antenna is presented in(Katoch et al., 2015) for IoT applications. In (Dong et al., 2017)a compact and novel printed antenna based on a folded strip is designed for $2.4 \mathrm{GHz}$ WLAN applications with extended bandwidth. A microstrip patch antenna array for IoT applications is presented in (Giay \& Alam, 2018). In Microstrip Antenna for IoT/WLAN applications in Smart Homes at 17GHz(Varum et al., 2018). However, all these research results present a low gain.

The aim of this work is to design a circular $2 * 1$ and $4 * 1$ array antennas for RFID reader which operates at $2.4 \mathrm{GHz}$, which will be used for IoT applications. The development of this array antenna improves the gain of the antenna.

In the first section, a single circular patch antenna was performed by CADFEKO, in the following sections, two and four elements of patch array antennas are studied and performed.

\section{SINGLE MICROSTRIP CIRCULAR PATCH ANTENNA DESIGN}

The proposed microstrip antenna has a circular shape that operates at $2.4 \mathrm{GHz}$. It is etched on one side of a standard FR4 dielectric substrate. The substrate material has a compact dimension of $W_{s}$ $\times L_{s} \times h$. A $50 \Omega$ microstrip line with an inset of y0 is used to excite the radiating circular patch. The radius of the circular microstrip patch was calculated by (1) (Balanis, 2005):

$$
a=\frac{F}{\sqrt{1+\frac{2 h}{\pi \cdot \varepsilon_{r} \cdot F}\left[\ln \left(\frac{\pi \cdot F}{2 h}\right)+1.7726\right]}}
$$

Where:

$$
F=\frac{8.791 \times 10^{9}}{f_{r} \cdot \sqrt{\varepsilon_{r}}}
$$

$\varepsilon_{r}$ : dielectric constant of the substrate.

$f_{r}$ : the resonance frequency

By applying the previous equation and after optimization with CADFEKO, the radius of the circular patch antenna with a resonant frequency of $2.4 \mathrm{GHz}$ is $a=17.3 \mathrm{~mm}$.

Figure 1 presents the designed basic patch antenna structure and table.1 illustrates the dimensions of the patch antenna.

The simulation results obtained by CADFEKO solver for the designed circular microstrip patch antenna in terms of reflection coefficient S11, input impedance, far-fields E-plane, H-plane and 3D radiation patterns at $2.4 \mathrm{GHz}$ are shown respectively in Figures 2, 3,4and 5.

The simulation result found by CADFEKO of the designed patch antenna is shown in figure 2. it provides the resonant frequency at $2.4 \mathrm{GHz}$ with a reflection coefficient of $-19.87 \mathrm{~dB}$. The simulated impedance bandwidth is about $30 \mathrm{MHz}(2.39-2.42 \mathrm{GHz})$.

Figure 3 illustrates the simulated input impedance of the designed patch antenna versus frequency. At $2.4 \mathrm{GHz} Z=51+\mathrm{j} 2 \Omega$, this result confirmed that the designed antenna is well adapted. The simulated results $\mathrm{E}$ and $\mathrm{H}$ planes radiation patterns are presented in figure 4. It is shown from the figure that 
Figure 1. geometry of the designed basic antenna

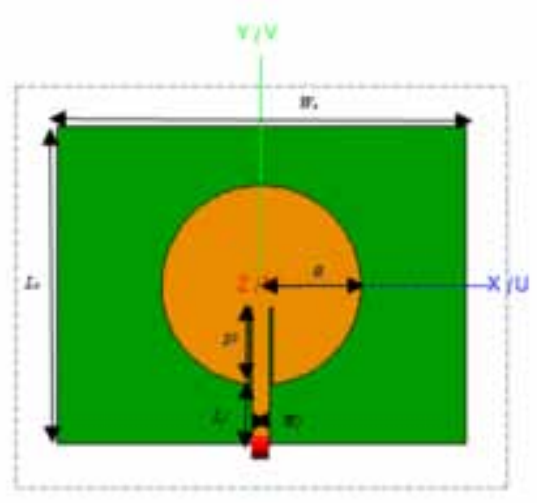

Table 1. Parameters of the designed basic antenna

\begin{tabular}{|l|l|}
\hline \multicolumn{1}{|c|}{ Parameters } & Dimensions $(\mathrm{mm})$ \\
\hline$W_{s}$ & 71 \\
\hline$L_{s}$ & 55 \\
\hline$a$ & 17.3 \\
\hline$L_{f}$ & 10.15 \\
\hline$W_{f}$ & 3 \\
\hline$y_{0}$ & 13.5 \\
\hline
\end{tabular}

Figure 2. Simulated reflection coefficient $S_{11}$ versus frequency

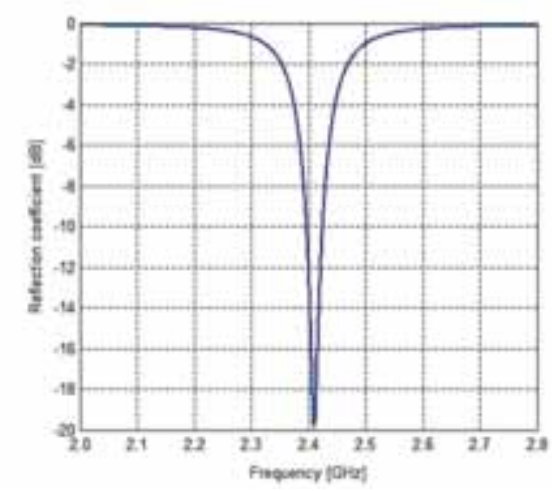


International Journal of Web-Based Learning and Teaching Technologies Volume 17 • Issue 5

Figure 3. Simulated real and imaginary impedance versus frequency;

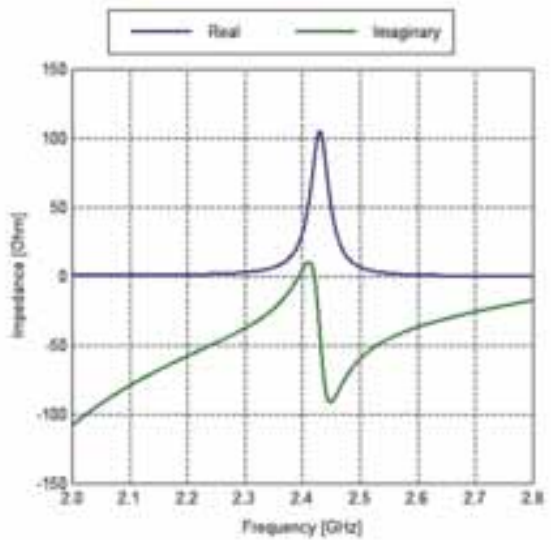

Figure 4. Simulated $\mathrm{E}$ and $\mathrm{H}$ planes of the designed patch antenna at $2.40 \mathrm{GHz}$

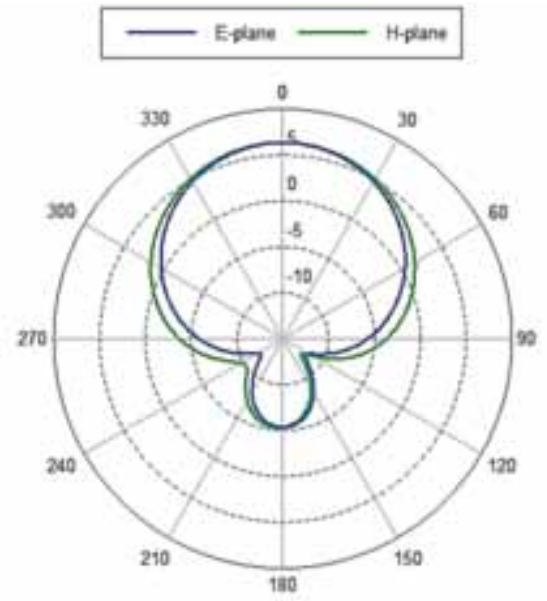

Figure 5. 3D radiation pattern of the designed patch antenna at $2.4 \mathrm{GHz}$

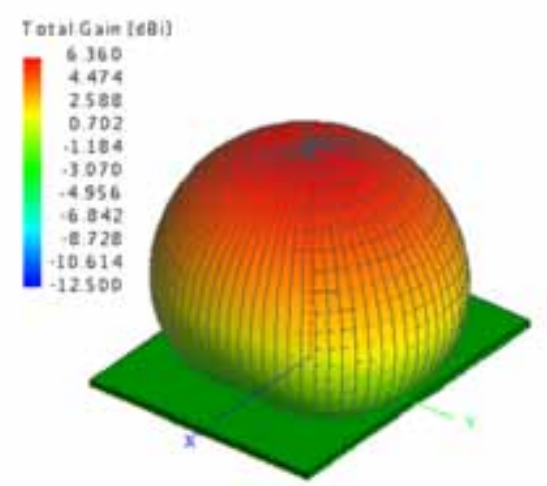


the E-plane and H-plane radiation patterns are directional at 2.4 GHz. The 3D radiation pattern is given in figure 5 with a maximum gain of $6.36 \mathrm{~dB}$.

\section{CIRCULAR MICROSTRIP PATCH ARRAY ANTENNA DESIGN}

\section{Design And Analysis Of A 2*1 Array}

The proposed array antenna structure $2 \times 1$ is depicted in figure 6 . Each circular radiating patch has the same radius as used above in order to increase the antenna performances.

Figure 6. geometry of the designed $2 * 1$ array antenna

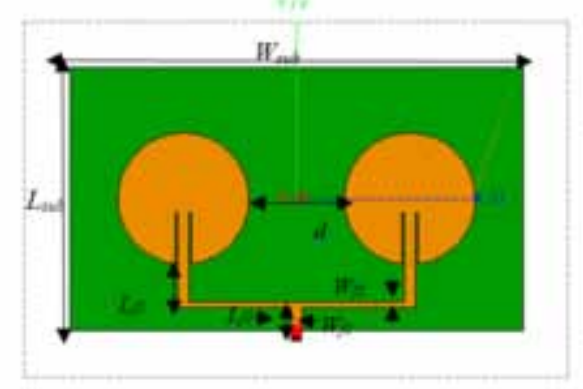

Table 2. Parameters of the designed $2 * 1$ array antenna

\begin{tabular}{|l|l|}
\hline \multicolumn{1}{|c|}{ Parameters } & Dimensions $(\mathrm{mm})$ \\
\hline$W_{\text {sub }}$ & 119.2 \\
\hline$L_{\text {sub }}$ & 55 \\
\hline$d$ & 25 \\
\hline$L_{f 1}$ & 5.8 \\
\hline$W_{f 1}$ & 3 \\
\hline$W_{f 2}$ & 1.6 \\
\hline$L f_{2}$ & 11.5 \\
\hline
\end{tabular}

The proposed array is printed in FR4 substrate with a thickness h. The distance separated the circular radiating patch is $\mathrm{d}$. The dimensions of the proposed $2 \times 1$ array antenna are resented in table 2 .

Figure 7 shows the variation of the reflection coefficient S11. It is observed that the antenna resonance at frequency $2.4 \mathrm{GHz}$ with a reflection coefficient of $-42.42 \mathrm{~dB}$. And the simulated impedance bandwidth is about $45 \mathrm{MHz}(2.375-2.42 \mathrm{GHz})$. Figure 8 shows the simulated $\mathrm{f}$ E-plane and $\mathrm{H}$-plane at $2.4 \mathrm{GHz}$ for the designed $2 * 1$ circular array antenna. From the figure we observe that E-plane and H-plane are directional. Figure 9 shows the 3D radiation pattern. It has observed from the figure that the maximum gain is $8.1 \mathrm{~dB}$. 
International Journal of Web-Based Learning and Teaching Technologies Volume 17 • Issue 5

Figure 7. Simulated reflection coefficient $S_{11}$ versus frequency of the designed $2 * 1$ array antenna

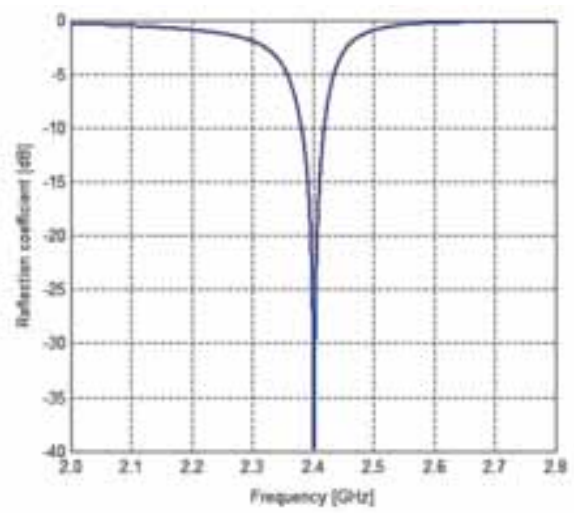

Figure 8. Simulated $\mathrm{E}$ and $\mathrm{H}$ planes of the designed $2 * 1$ array antenna at $2.4 \mathrm{GHz}$

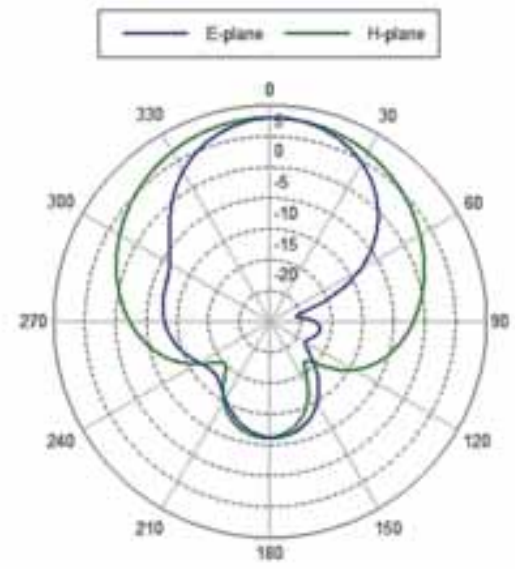

Figure 9. 3D radiation pattern of the designed $2 * 1$ array antenna at $2.4 \mathrm{GHz}$

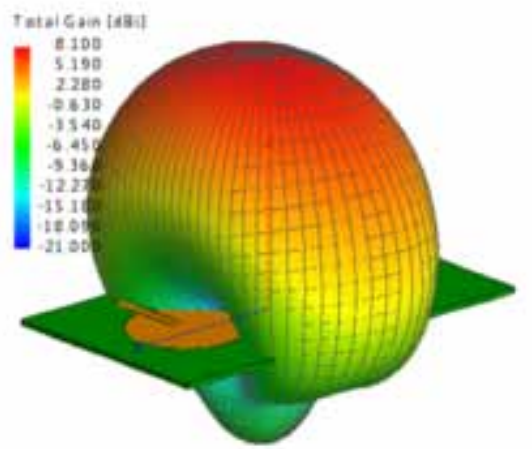




\section{Design And Analysis Of A 4*1 Array}

Here, in order to enhanced the radiation characteristics of an identical four circular radiating patches used in the first section of this work. Figure 10. presents the geometry of the designed $4 * 1$ array antenna and the dimensions of the different parameters are shown in Table 3.

The simulation results acquired for the designed $4 * 1$ array antenna in terms of reflection coefficient by using CADFEKO is depicted in Figure 10. It is also noted from the figure that the antenna can operate at $2.4 \mathrm{GHz}$ with reflection coefficient of $-29.7 \mathrm{~dB}$. And a bandwidth of $51 \mathrm{MHz}$. The E-plane and $\mathrm{H}$-plane radiation patterns at $2.4 \mathrm{GHz}$ are presented in figure 11 . it is noticed from

Figure 10 . geometry of the designed $4 * 1$ array antenna

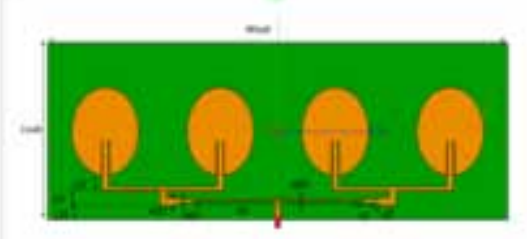

Table 3. Parameters of the designed $4 * 1$ array antenna

\begin{tabular}{|l|l|}
\hline \multicolumn{1}{|c|}{ Parameters } & Dimensions $(\mathrm{mm})$ \\
\hline$W_{\text {sub }}$ & 238.4 \\
\hline$L_{\text {sub }}$ & 55 \\
\hline$d 1$ & 25 \\
\hline$d 2$ & 8.6 \\
\hline$d 3$ & 8.6 \\
\hline$L_{f 1}$ & 7.1 \\
\hline$W_{f 1}$ & 3 \\
\hline$L_{f 2}$ & 5.8 \\
\hline$W f_{2}$ & 1.6 \\
\hline
\end{tabular}

Figure 11. Simulated reflection coefficient $S_{11}$ versus frequency of the designed $4 * 1$ array antenna

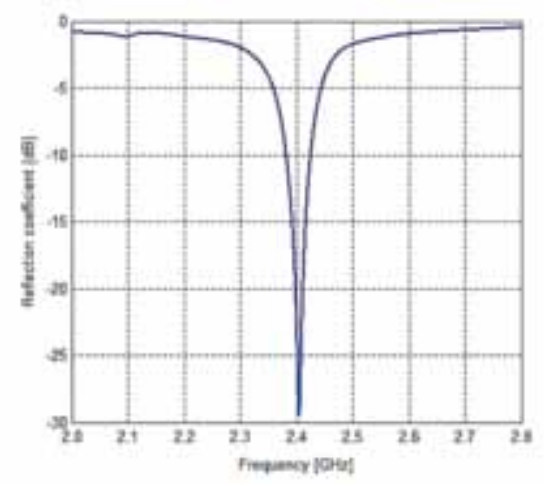


the figure that the directional behavior of the designed antenna at the resonant frequency $2.4 \mathrm{GHz}$ was preserved. The 3D radiation pattern is presented in Figure 12 and the maximum gain is $10.29 \mathrm{~dB}$.

Figure 12. Simulated $\mathrm{E}$ and $\mathrm{H}$ planes of the designed $4^{*} 1$ array antenna at $2.4 \mathrm{GHz}$

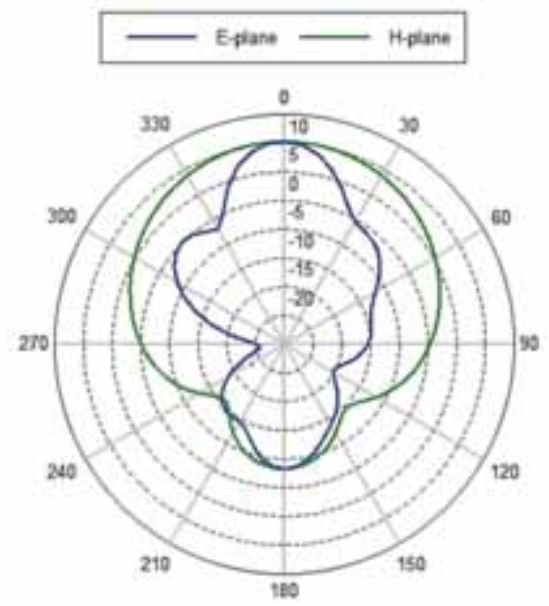

\section{SUMMARY OF SIMULATION RESULTS AND DISCUSSION}

Table. 4 gives a performances comparison of the designed circular basic antenna with the $2 * 1$ and $4 * 1$ array antennas. The parameters that compared are the resonant frequency, the reflection coefficient, the gain and the bandwidth.

The designed $2 * 1$ and $4 * 1$ array antennas provide a good impedance matching at $2.4 \mathrm{GHz}$.

The bandwidth enhanced into $45 \mathrm{MHz}$ for $2 * 1$ array antenna, while for the $4 * 1$ array antenna it was improved into $51 \mathrm{MHz}$. Also, it is observed from the table that the $2 * 1$ array, while for the $4 * 1$ array antenna has a gain of $10.29 \mathrm{~dB}$. From that, it is noticed from the table that the use of four elements has increased the antenna gain and bandwidth more than the two elements.

Figure 13. 3D radiation pattern of the designed $4 * 1$ array antenna at $2.4 \mathrm{GHz}$

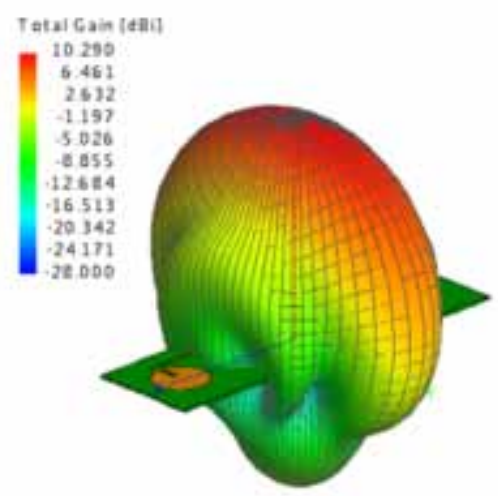


Table 4. Summary of simulation results

\begin{tabular}{|c|c|c|c|}
\hline & Circular basic antenna & $\mathbf{2 * 1}$ array antenna & $\mathbf{4 * 1}$ array antenna \\
\hline $\boldsymbol{f}_{\boldsymbol{r}}$ & $2.4 \mathrm{GHz}$ & $2.4 \mathrm{GHz}$ & $2.4 \mathrm{GHz}$ \\
\hline $\boldsymbol{S}_{\boldsymbol{1 I}}$ & $-19.87 \mathrm{~dB}$ & $-42.42 \mathrm{~dB}$ & $-29.7 \mathrm{~dB}$ \\
\hline Bandwidth & $30 \mathrm{MHz}$ & $45 \mathrm{MHz}$ & $51 \mathrm{MHz}$ \\
\hline Gain & $6.36 \mathrm{~dB}$ & $8.1 \mathrm{~dB}$ & $10.29 \mathrm{~dB}$ \\
\hline
\end{tabular}

\section{Conclusion}

This paper presents the design $2 * 1$ and $4 * 1$ RFID reader array antenna operates at $2.4 \mathrm{GHz}$, for Zigbee, Bluetooth, and WIFI correspond to IoT applications. The antenna was performed using CADFEKO. The $4 * 1$ configuration presents a good performance in terms of gain and bandwidth compared with the designed single and $2 * 1$ array antenna. The increase in the number of radiating elements improves the antenna performances especially the gain. This structure will be a good solution for IoT applications. As perspective of this work, fabrication and measurement should be done to confirm the simulated results. 


\section{REFERENCES}

Alami, A. E., Bennani, S. D., Bekkali, M. E., \& Benbassou, A. (2005). Design, analysis and optimization of a new structure of microstrip patch antenna for RFID applications. Academic Press.

Balanis, C. A. (2005). Antenna theory: Analysis and design (3rd ed.). John Wiley.

Chen, Z. N., \& Qing, X. (2010). Antennas for RFID applications. 2010 International Workshop on Antenna Technology (IWAT), 1-4. doi:10.1109/IWAT.2010.5464865

Dong, Y., Choi, J., \& Itoh, T. (2017). Folded Strip/Slot Antenna with Extended Bandwidth for WLAN Application. IEEE Antennas and Wireless Propagation Letters, 16, 673-676. doi:10.1109/LAWP.2016.2598276

El Alami, A., Ghazaoui, Y., Das, S., Bennani, S. D., \& Ghzaoui, M. E. (2019). Design and Simulation of RFID Array Antenna 2x1 for Detection System of Objects or Living Things in Motion. Procedia Computer Science, 151, 1010-1015. doi:10.1016/j.procs.2019.04.142

Fahmy, A., Altaf, H., Al Nabulsi, A., Al-Ali, A., \& Aburukba, R. (2019). Role of RFID Technology in Smart City Applications. 2019 International Conference on Communications, Signal Processing, and their Applications (ICCSPA), 1-6. doi:10.1109/ICCSPA.2019.8713622

Giay, Y., \& Alam, B. R. (2018). Design and Analysis 2.4 GHz Microstrip Patch Antenna Array for IoT Applications using Feeding Method. 2018 International Symposium on Electronics and Smart Devices (ISESD), 1-3. doi:10.1109/ISESD.2018.8605455

Ikram, T., Najiba, E. A. E. I., Jorio, M., \& Slimani, A. (2017). A high gain $1 * 2$ array RFID reader MPA for indoor localization applications. 2017 International Conference on Wireless Technologies, Embedded and Intelligent Systems (WITS), 1-6. doi:10.1109/WITS.2017.7934639

Katoch, S., Jotwani, H., Pani, S., \& Rajawat, A. (2015). A compact dual band antenna for IOT applications. 2015 International Conference on Green Computing and Internet of Things (ICGCIoT), 1594-1597. doi:10.1109/ ICGCIoT.2015.7380721

Khardioui, M., Bamou, A., El Ouadghiri, M. D., \& Aghoutane, B. (2020). Implementation and Evaluation of an Intrusion Detection System for IoT : Against Routing Attacks. In M. Ezziyyani (Ed.), Advanced Intelligent Systems for Sustainable Development (AI2SD’2019) (Vol. 92, pp. 155-166). Springer International Publishing. doi:10.1007/978-3-030-33103-0_16

Nate, K., \& Tentzeris, M. M. (2015). A novel 3-D printed loop antenna using flexible NinjaFlex material for wearable and IoT applications. 2015 IEEE 24th Electrical Performance of Electronic Packaging and Systems (EPEPS), 171-174. 10.1109/EPEPS.2015.7347155

Nate, K. A., Hester, J., Isakov, M., Bahr, R., \& Tentzeris, M. M. (2015). A fully printed multilayer aperturecoupled patch antenna using hybrid 3D / inkjet additive manufacturing technique. 2015 European Microwave Conference (EuMC), 610-613. doi:10.1109/EuMC.2015.7345837

Ouazzani, O., Bennani, S. D., \& Jorio, M. (2017). Design and simulation of $2 * 1$ and $4 * 1$ array antenna for detection system of objects or living things in motion. 2017 International Conference on Wireless Technologies, Embedded and Intelligent Systems (WITS), 1-5. doi:10.1109/WITS.2017.7934640

Varum, T., Duarte, M., Matos, J. N., \& Pinho, P. (2018). Microstrip Antenna for IoT/WLAN applications in Smart Homes at 17GHz. 12th European Conference on Antennas and Propagation (EuCAP 2018), 116. doi:10.1049/ cp.2018.0475 
Omaima Benkhadda received the master's degree in electrical engineering in 2018 from Cadi Ayad University of Marrakech, Morocco. She is currently working toward the Ph. D degree at the Department of Electrical engineering and Automatic, Energy Conversion and Microelectronics Laboratory, Sultan Moulay Slimane university, Beni Mellal, Morocco. Her research interests include antenna design, numerical electromagnetics methods, microstrip antenna, array antenna and beam scanning antenna.

Mohamed Saih received the Dipl.-Ing. and Ph.D degrees in Electrical Systems and Telecommunications from Cadi Ayyad University, Marrakech in 2011 and 2017, respectively. From 2013 to 2018, He was a professor at Higher Institute of Engineering and Business. Since May 2018, he has been an associate professor at Sultan Moulay Slimane University, Béni Mellal, Morroco, where his major fields of research are Electromagnetic compatibility, Multiconductor transmission lines, Numerical electromagnetic methods, and Antenna designs.

Kebir Chaji was born in 1969 in Morocco. He is a professor of electrical engineering at the Sultan Moulay Slimane University since 1996.

Abdelati Reha was born in Casablanca-Morocco in 1975, he received the degree of engineer in aeronautic from the Royal Air Academy of Marrakech-Morocco in 1999, the degree of engineer in telecommunication from the INPTRabat-Morocco in 2002, the PHD degree in telecommunication from Hassan II University-Casablanca-Morocco in 2016. He is an Ex-Major in Moroccan Royal Air Forces. He is the head of telecommunication department in ISGA-Marrakech. His main research interests are in fractal antennas, UWB applications, array antennas. 